\title{
TGB A* state in a homologous series of diarylethane $\alpha$-chloroester ferroelectric liquid crystals
}

\author{
by I. DIERKING, F. GIEßELMANN and P. ZUGENMAIER* \\ Institut für Physikalische Chemie, TU Clausthal, \\ Arnold-Sommerfeld-Str. 4, D-38678 Clausthal-Zellerfeld, Germany
}

(Received 23 August 1993; accepted 8 November 1993)

\begin{abstract}
A twist grain boundary (TGB A*) or twisted smectic $\mathrm{A}^{*}$ state was observed in two compounds of a homologous series of diarylethane $\alpha$-chloroester ferroelectric liquid crystals. The phases have been characterized by optical polarizing microscopy and differential scanning calorimetry. Textures of the TGB A* state obtained by preparation on a glass slide and in thin homeotropically orienting liquid crystal cells or as free-standing films clearly show the helical structure, whereas preparation in homogeneously orienting LC cells suggests that the helical structure is suppressed by the cell geometry, in a similar way to that observed for $\mathrm{S}_{\mathrm{C}}^{*}$ phases in the surface stabilized geometry (SSFLCs).
\end{abstract}

\section{Introduction}

Recently the discovery of a novel smectic $\mathrm{A}^{*}$ variant, the twisted smectic $\mathrm{A}^{*}$ or twist grain boundary (TGB A*) phase [1], was reported by Goodby et al. [2,3]. In this paper we report on two compounds of a homologous series of diarylethane $\alpha$-chloroesters [4] ( $n=7,8$ ) derived from $D$-valine, which will be referred to as D7 and D8, having the general formula

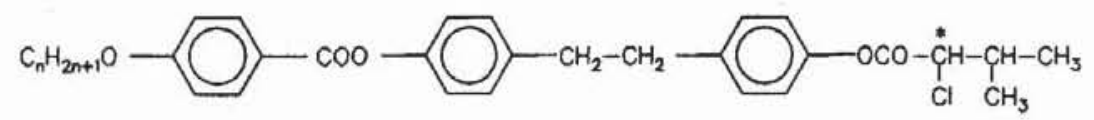

( $\mathrm{n}=7: \mathrm{D} 7 ; n=8: \mathrm{D} 8)$ which exhibit the phase sequences

$$
\begin{aligned}
& \text { D7: I } 133.2 \mathrm{~N}^{*} 121.1 \text { TGB A* } 120.8 \mathrm{~S}_{\mathrm{C}}^{*} 92.4 \mathrm{~S}_{\mathrm{I}}^{*} 86.1 \mathrm{~S}_{\mathrm{F}}^{*} \text {; } \\
& \text { D8: I } 134.5 \mathrm{~N}^{*} 129.4 \text { TGB } \mathrm{A}^{*} 129.2 \mathrm{~S}_{\mathrm{A}}^{*} 125.6 \mathrm{~S}_{\mathrm{C}}^{*} 92.9 \mathrm{~S}_{\mathrm{I}}^{*} 83.7 \mathrm{~S}_{\mathrm{F}}^{*} \text {. }
\end{aligned}
$$

The mesophases were identified by texture observation and comparison with results in [4]. The temperature control of the hot stage was within $0.1^{\circ} \mathrm{C}$ and the accuracy of absolute temperature values was about $1^{\circ} \mathrm{C}$. Since the distinctive invariant property of chiral phases, as compared to their non-chiral analogues, is the local symmetry, meaning the chirality itself and not the macroscopic helical structure [5], the notation $S_{A}^{*}$ is used to describe the chiral smectic A phase, that is the commonly observed smectic A phase, but one which is built up of chiral molecules, in contrast to the TGB A* state, which is built up of chiral molecules and exhibits a twisted layer configuration $[2,3]$.

* Author for correspondence. 


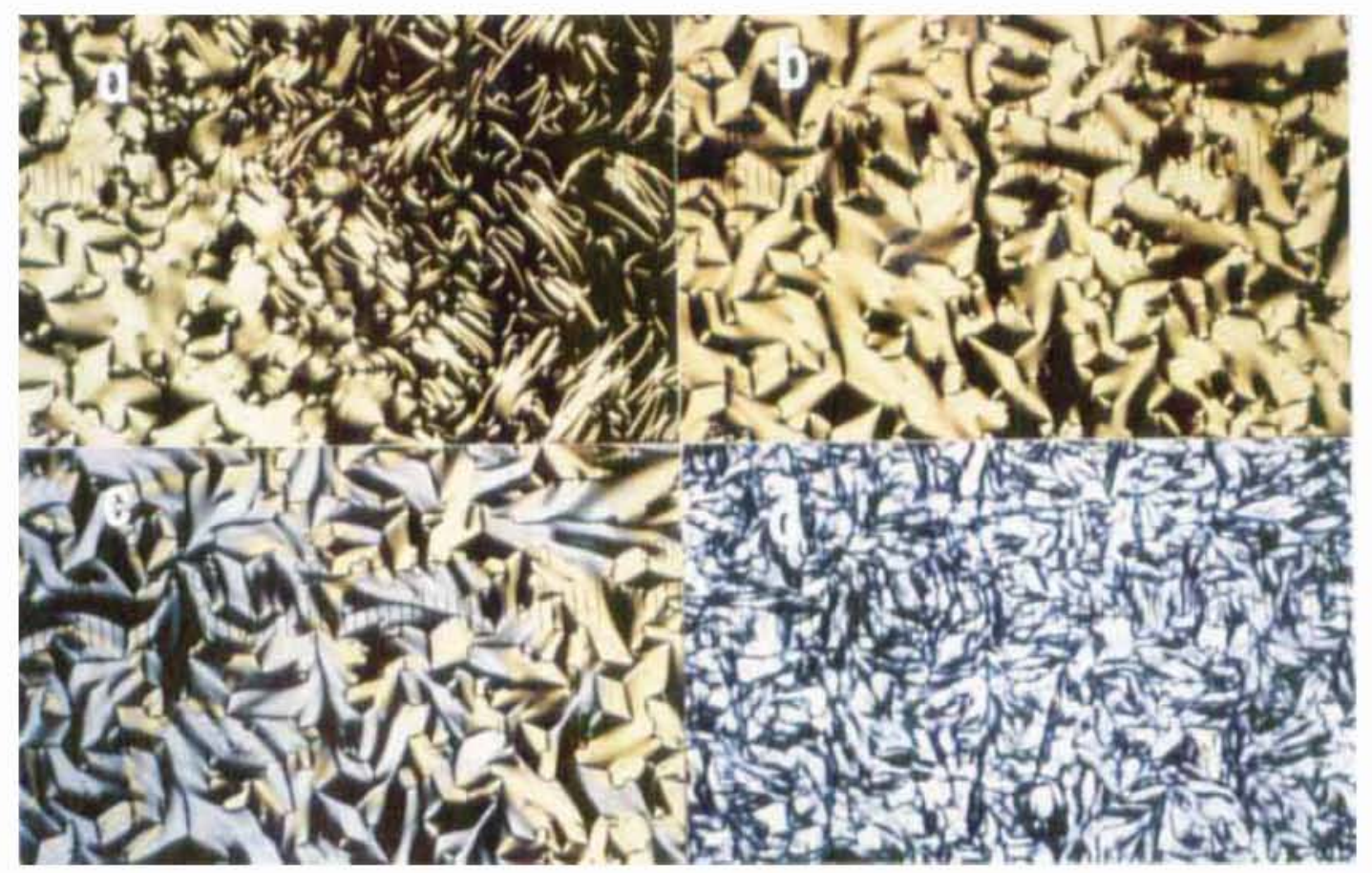

Figure 1. Polarizing optical micrographs of some mesophases of compound D8 contained in thin liquid crystal cells with homeotropic alignment layers. (a) Transition from the homeotropically aligned smectic $A^{*}$ phase (black texture) to the twisted $\mathrm{S}_{\mathrm{A}}^{*}$ state (TGB A* state) (yellow line texture, $T=125 \cdot 9^{\circ} \mathrm{C}$. (b) The TGB A* state at $T=126 \cdot 0^{\circ} \mathrm{C}$. (c) Transition from the TGB A* state (yellow texture) to the cholesteric phase (grey texture) at $T=126 \cdot 15^{\circ} \mathrm{C} .(d)$ Texture of the cholesteric phase at $T=126 \cdot 5^{\circ} \mathrm{C}(10$ units of scale $\triangleq 60 \mu \mathrm{m}$ ).

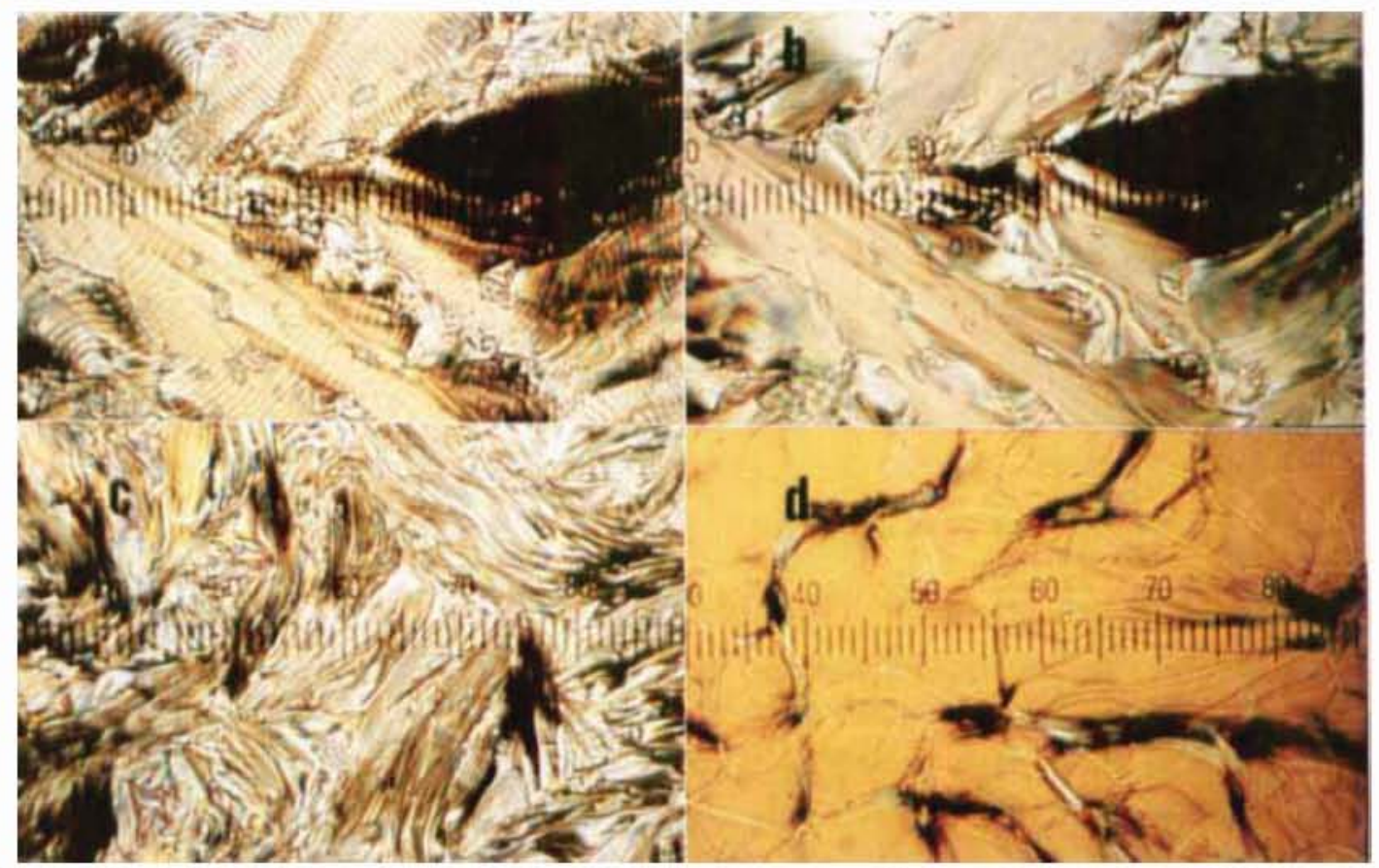

Figure 2. Polarizing optical micrographs of some mesophases of compound D8 mounted between two untreated glass slides. (a) smectic $\mathrm{C}^{*}$ phase with typical disclination lines, $T=125.6^{\circ} \mathrm{C},(b)$ fan-shaped smectic A* texture, $T=128.9^{\circ} \mathrm{C},(c)$ line texture of the TGB A* state, $T=129 \cdot 2^{\circ} \mathrm{C}$ and $(d)$ oily streak texture of the cholesteric phase at $T=129.5^{\circ} \mathrm{C}$ (10 units of scale $\triangleq 60 \mu \mathrm{m}$ ). 

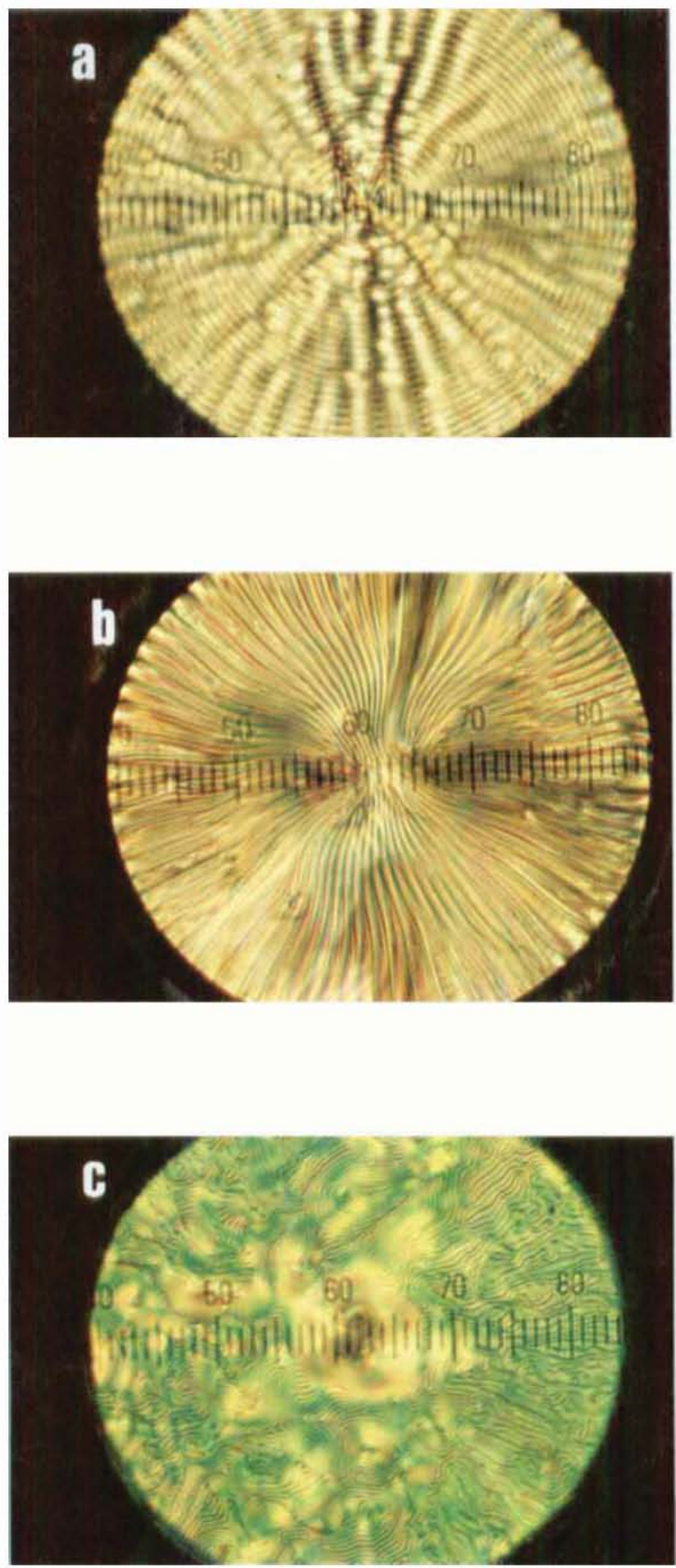

Figure 3. Polarizing optical micrographs of some mesophases of compound D7 mounted as a small droplet between two untreated glass slides. (a) Smectic $\mathrm{C}^{*}$ phase with disclination lines arranged in a concentric fashion, $T=121.0^{\circ} \mathrm{C},(b) \mathrm{TGB}$ A* state, $T=121.5^{\circ} \mathrm{C}$; the disclination lines are arranged in a spherulite-like manner, $(c)$ fingerprint texture of the cholesteric phase at $T=122 \cdot 3^{\circ} \mathrm{C}(10$ units of scales $\triangleq 60 \mu \mathrm{m})$. 
A similar homologous series was first synthesized from $L$-valine by Nguyen et al. [4], but they did not report any observations on TGB A* states. This is most likely due to differences in optical purities, since the optical purity has a great influence on the stability and temperature range of the TGB A* phase $[6,7]$.

\section{Experimental}

Polarizing optical microscopic studies were carried out with an Olympus $\mathrm{BH}-2$ microscope equipped with a Mettler FP 52 hot stage and a Mettler FP 5 temperature controller. The textures of phases possessing a helical $\mathrm{S}_{\mathrm{A}}^{*}$ structure were investigated by preparing the samples on slides without surface alignment layers and in commercially available liquid crystal cells (E.H.C. Co. Ltd., cell gap $4 \mu \mathrm{m}$ ) with homeotropic aligning surface layers and as free-standing films. The surface induced unwinding of the helical structure of the TGB A* state was studied by preparing samples in commercially available liquid crystal cells (E.H.C. Co. Ltd., cell gap $4 \mu \mathrm{m}$ ) with homogeneous aligning surface layers.

Calorimetric investigations were carried out with a differential scanning calorimeter (Perkin Elmer DSC7) at variable heating and cooling rates of $\pm 1, \pm 2$ and $\pm 5^{\circ} \mathrm{C} \mathrm{min}{ }^{-1}$ and different sample masses from $2-8 \mathrm{mg}$.

\section{Experimental results and discussion}

Compounds D7 and D8 exhibit the phase sequences given above; these are slightly different from those reported in the literature [4], since a TGB A* state over a small temperature interval of about $0.2^{\circ} \mathrm{C}$ was detected by polarizing optical microscopy for both substances. The TGB A* state mediates the smectic $\mathrm{A}^{*}$ to cholesteric transition in D8 and the smectic $\mathrm{C}^{*}$ to cholesteric transition in D7.

Figure $1(a)-(d)$ depicts some of the liquid crystalline phases of compound D8, observed by polarizing optical microscopy on heating samples prepared in liquid crystal cells with homeotropic alignment layers. Figure $1(a)$ shows the transition from the non-helical, homeotropically aligned smectic $\mathrm{A}^{*}$ phase (black texture, $T=125.9^{\circ} \mathrm{C}$ ) to the helical TGB $A^{*}$ state (yellow line texture, see also $[3,6,8]$ ). The transition is accompanied by the formation of a characteristic filament texture, which is completely developed at $T=126^{\circ} \mathrm{C}$ (see figure $1(b)$ ). The transition from the helical TGB A* state (yellow texture) to the cholesteric phase (grey texture) is shown in figure $1(c)$ at $T=126 \cdot 15^{\circ} \mathrm{C}$ and clearly detected by the change in the interference colour due to the variation of the birefringence. Figure $1(d)$ depicts the $\mathrm{N}^{*}$ phase at $T=126 \cdot 5^{\circ} \mathrm{C}$. Preparation of compound D8 on slides without surface alignment layers produces textures which also reveal the existence of an intermediary state between the commonly observed non-helical, chiral $\mathrm{S}_{\mathrm{A}}^{*}$ phase and the cholesteric phase, as depicted in figure $2(a)-(d)$. Figure $2(a)$ shows a typical fan-shaped texture of the ferroelectric $\mathrm{S}_{\mathrm{C}}^{*}$ phase with lines due to the helical director configuration $[9,10]$ (see plate 164 in [11]) at temperature $T=125 \cdot 6^{\circ} \mathrm{C}$. On passing through the transition temperature into the non-helical, chiral smectic $\mathrm{A}^{*}$ phase, the lines disappear and a fan-shaped texture of the $S_{\mathrm{A}}^{*}$ phase (see plates 99 and 105 in [11]) is observed (see figure $2(b), T=128.9^{\circ} \mathrm{C}$ ). Mediating the chiral smectic $A^{*}$ phase and the cholesteric phase, the formation of a lined texture, due to the layer twist of the TGB A* state can be seen (see figure $2(c)$, $T=129 \cdot 2^{\circ} \mathrm{C}$ ), before, on further heating, the typical oily-streak texture (see plates 21 and 22 in [11]) of the cholesteric phase (see figure $2(d), T=129.5^{\circ} \mathrm{C}$ ) appears. The transition temperatures are somewhat different from the ones observed by preparation of the sample in thin liquid crystal cells, which is most likely due to strong surface 
interactions in thin LC cells [10]. Observation of free-standing films between crossed polarizers revealed the same characteristic filament textures of the TGB A* state as those observed by Goodby et al. [3].

Figure 3(a)-(c) depicts some of the mesophases of compound D7 mounted as a small droplet between two untreated glass slides. Figure $3(a)$ shows the smectic $C^{*}$ phase at temperature $T=121.0^{\circ} \mathrm{C}$. The disclination lines due to the helical structure of the phase are arranged as concentric rings, since the helical axis of the $S_{C}^{*}$ phase lies perpendicular to the smectic layers. Figure $3(b)$ depicts the same droplet in the TGB A* state at $T=121 \cdot 5^{\circ} \mathrm{C}$. The photograph exhibits a line texture with lines arranged in a spherulite-like, radial fashion, as the helical axis of the configuration has turned $90^{\circ}$, compared to the helical axis of the $\mathrm{S}_{\mathrm{C}}^{*}$ phase. Passing through the transition into the cholesteric phase, a finger-print texture appears (see figure $3(\mathrm{c}), T=122 \cdot 3^{\circ} \mathrm{C}$ ). A non-helical, chiral smectic $A^{*}$ phase ( $S_{A}^{*}$ phase), in addition to the twisted TGB $A^{*}$ state as observed for D8, was not detected for this compound by preparation of the sample on slides without alignment layers.

Calorimetric studies at variable heating and cooling rates showed that for compound $\mathrm{D} 8$, the $\mathrm{S}_{\mathrm{C}}^{*} \rightarrow \mathrm{S}_{\mathrm{A}}^{*}$ and the TGB $\mathrm{A}^{*} \rightarrow \mathrm{N}^{*}$ transitions are clearly detected, whereas the transition from $\mathrm{S}_{\mathrm{A}}^{*}$ to TGB $\mathrm{A}^{*}$ cannot be observed within the experimental resolution. For compound D7, the transitions $\mathrm{S}_{\mathrm{C}}^{*} \rightarrow$ TGB $\mathrm{A}^{*}$ and TGB $\mathrm{A}^{*} \rightarrow \mathrm{N}^{*}$ could be detected. This suggests, that the transitional enthalpy change between the $S_{A}^{*}$ and the TGB $A^{*}$ phase is very small, like the energy barrier between the helical $S_{C}^{*}$ phase and the corresponding surface stabilized geometry [12]. An analogous behaviour can also be observed for cholesteric systems with temperature induced helix inversion, where the twist inversion cannot be detected by DSC [13].

Further evidence that the energy barrier for the change from $S_{A}^{*}$ to TGB $A *$ is very small can be found by preparing the samples in thin liquid crystal cells with homogeneous surface alignment layers. Very well-oriented, defect-free alignment is obtained for compound D8 by slowly cooling the sample from the isotropic phase. The transition from $\mathrm{S}_{\mathrm{A}}^{*}$ to TGB $\mathrm{A}^{*}$ is no longer observed, as no change in the appearance of the texture is detected. The sample can be brought into an optically extinct position by rotating the cell between crossed polarizers, just as is the case for a normal, non-helical $S_{A}^{*}$ phase. For compound D7, a defect-free, very well-oriented sampled appears, without the fingerprint-like line textures which were observed by preparing the sample on slides without alignment layers or in cells with homeotropic alignment layers. The helical structure of the TGB A* phase seems to be suppressed by the cell geometry, in an analogous way to that in a SSFLC cell.

\section{Conclusions}

In contrast to reports on diarylethane $\alpha$-chloroesters in the literature [4], we have detected a TGB $A^{*}$ state, which mediates the $S_{C}^{*}$ and $N^{*}$ phases in compound $D 7$ and the $\mathrm{S}_{\mathrm{A}}^{*}$ and $\mathrm{N}^{*}$ phases in compound D8. Calorimetric studies and texture observation of samples in thin liquid crystal cells suggest that the TGB A* state can be suppressed by an appropriate cell geometry, as it is found in SSFLC cells. It should be noted, that the formation of the TGB state of the $S_{A}^{*}$ phase is very sensitive to conditions of preparation of the sample.

This work was supported by a grant from the Deutsche Forschungsgemeinschaft. The compounds were kindly supplied by Dr J. Kußerow, Institut für Organische Chemie der Technischen Universität Clausthal. 


\section{References}

[1] Renn, S. R., and Lubensky, T. C., 1988, Phys. Rev. A, 38, 2132.

[2] Goodby, J. W., Waugh, M. A., Stein, S. M., Chin, E., Pindak, R., and Patel, J. S., 1989, Nature, Lond., 337, 449.

[3] Goodby, J. W., Waugh, M. A., Stein, S. M., Chin, E., Pindak, R., and Patel, J. S., 1989, J. Am. chem. Soc., 111, 8119.

[4] Nguyen, H. T., Babeau, A., Léon, C., Marcerou, J.-P., Destrade, C., Soldera, A., Gulllon, D., and Skoulios, A., 1991, Liq. Crystals, 9, 253.

[5] Lagerwall, S. T., 1988, Ferroelectrics, 85, 497.

[6] Slaney, A. J., and GoodBy, J. W., 1991, J. mater. Chem., 1, 5.

[7] Slaney, A. J., and Goodby, J. W., 1991, Liq. Crystals, 9, 849.

[8] Patel, J. S., LeE, S.-D., SuH, S.-W., and Goodby, J. W., 1993, Liq. Crystals, 13, 313.

[9] Martinot-Lagarde, Ph., 1976, J. Phys., Paris, 37, C3-129.

[10] Martinot-Lagarde, Ph., Duke, R., and Durand, G., 1981, Molec. Crystals liq. Crystals, 75, 249.

[11] Demus, D., and Richter, L., 1978, Textures of Liquid Crystals (Verlag Chemie).

[12] Clark, N. A., and Lagerwall, S. T., 1980, Appl. Phys. Lett., 36, 899.

[13] Dierking, I., Giebelmann, F., Zugenmaier, P., Kuczynski, W., Lagerwall, S. T., and STEBLER, B., 1993, Liq. Crystals, 13, 45. 